Revista Destaques Acadêmicos, Lajeado, v. 8, n. 3, 2016. ISSN 2176-3070 DOI: http://dx.doi.org/10.22410/issn.2176-3070.v8i3a2016.1165 www.univates.br/revistas

\title{
CÂNCER DE PRÓSTATA E SUA RELAÇÃO COM A SEXUALIDADE MASCULINA: PRODUÇÃO CIENTÍFICA BRASILEIRA
}

\author{
Ricardo Bastos de Lima ${ }^{1}$, Giselda Veronice Hahn²
}

\begin{abstract}
Resumo: $\mathrm{O}$ câncer de próstata $(\mathrm{CaP})$ é uma doença maligna que está comumente ligada ao avanço da idade dos homens. Trata-se de uma doença que não se restringe somente a próstata, mas que toca sua identidade, construída sob o modelo hegemônico de masculinidade, e abrange aspectos culturais, simbólicos, sociais e econômicos. Abordar a saúde do homem implica falar em sexualidade masculina e masculinidades. Este estudo tem por objetivo analisar as contribuições da produção científica sobre as repercussões do tratamento do $\mathrm{CaP}$ na sexualidade masculina publicadas entre os anos de 2006 e 2015, disponível em periódicos on-line. Para tanto, foi realizada uma revisão integrativa de literatura nas bases de dados Literatura Latino-Americana e do Caribe em Ciências da Saúde (LILACS) e Scientific Eletronic Library Online (SCIELO), utilizando os descritores Neoplasia de próstata e Sexualidade, publicados em português. Concluise que o adoecimento do homem pelo $\mathrm{CaP}$ representa uma ameaça a sexualidade e ao modelo hegemônico de masculinidade devido a "simbologia" atribuída a próstata.
\end{abstract}

Palavras-chave: Sexualidade. Próstata. Neoplasias da próstata.

\section{INTRODUÇÃO}

No Brasil, o câncer de próstata $(\mathrm{CaP})$ é um dos cânceres que mais acomete os homens, representando $10 \%$ dos casos. O CaP ocupa o segundo lugar no Brasil e o sexto no mundo, perdendo apenas para o câncer de pele nãomelanoma. Segundo o Instituto Nacional de Câncer (INCA), o CaP apresenta 70,42 novos casos a cada 100 mil homens, sendo a idade acima de 65 anos o principal fator de risco. Sua ocorrência é maior nos países desenvolvidos do que nos em desenvolvimento. Em 2014, foram detectados aproximadamente 68.800 casos de CaP no Brasil (INCA, 2015). Segundo Lopes, Chamas e Lyeyasu

1 Enfermeiro. Egresso do curso de Enfermagem do Centro Universitário UNIVATES.

2 Enfermeira. Mestre e doutora em enfermagem. Docente no Centro Universitário UNIVATES. 
(2013, p. 61), "[...] no mundo, o câncer de próstata representa $14 \%$ de todos os casos incidentes de câncer e $6 \%$ das mortes".

A próstata cresce lentamente até a puberdade, quando passa a crescer rapidamente até por volta dos 30 anos, assim permanecendo até os 45 anos, quando poderá apresentar crescimento extra (TORTORA; DERRICKSON, 2012). A próstata produz fluido rico em enzimas, citrato e o PSA (Antígeno Prostático Específico), essenciais para a fecundação. Esse líquido corresponde a um terço do total do sêmen, sendo eliminado durante a ejaculação, cuja função é ativar os espermatozoides (MARIEB; HOEHN, 2009).

O CaP é uma patologia que está comumente ligada ao avanço da idade do homem, cujo auge de incidência abrange os 70 anos (GUIMARÃ̃ES; ROSA, 2008). Entre os fatores de risco, além da idade, estão histórico familiar, dieta, obesidade e etnia. Indivíduos que moram em regiões onde o sol é predominante produzem mais Vitamina $\mathrm{D}$ e estão menos propensos a desenvolver $\mathrm{CaP}$ (HOLICK, 2012). O padrão histológico mais comum de CaP é o adenocarcinoma, representando mais de 90\% dos casos (BARACAT; FERNANDES JR.; SILVA, 2000).

Grande parcela dos homens apresentam-se assintomáticos ao $\mathrm{CaP}$ devido ao crescimento lento do tumor. Segundo Lima, Câmara e Fonseca (2014, p.180) "[...] Atualmente, cerca de $80 \%$ dos indivíduos são assintomáticos ao diagnóstico, enquanto uma minoria já se apresenta com alterações clínicas que refletem a doença localmente avançada metastática". Quando detectado em fases iniciais, a possibilidade de cura ou de estagnação da doença é maior. As manifestações clínicas variam individualmente, a origem do CaP e o surgimento de metástases prévias dificultam a cura da doença (SANTOS; MELLO, 2008).

[...] O Câncer de Próstata, em geral, tem evolução lenta e permanece assintomático em boa parte dos pacientes. Entretanto, sua história natural pode ser muito variável, com o aparecimento precoce de metástases, etapa em que a cura se torna quase impossível. As campanhas de detecção precoce e divulgação de conhecimentos aumentaram o interesse sobre o carcinoma prostático, reconhecido como a neoplasia mais frequente entre os homens com mais de 50 anos. O diagnóstico, em estádios iniciais, tem sido estabelecido com mais frequência, o que oferece oportunidades de cura ou então maior controle da doença (SANTOS; MELLO, 2008, p. 745-746).

Quando houver suspeita de CaP, o diagnóstico é feito mediante três principais exames: exame do toque digitálico da próstata, por meio do toque retal, que busca palpar nódulos enrijecidos; o exame de Dosagem Sérica do PSA, que resulta em mensurar o tamanho da próstata e progressão da doença; e o ultrassom transretal (UTR), com a capacidade de mostrar lesões que causam pouco eco no sonograma. A doença é confirmada por meio de biópsia, por ultrassom transretal e análise anatomopatológica do material coletado 
(POLLOCK et al., 2006). A análise anatomopatológica laboratorial do material coletado e o escore de Gleason são essenciais para identificar o grau em que se encontra a doença (LOPES; CHAMMAS; IYEYASU, 2013).

O PSA “é uma enzima glicoproteína que liquidifica o sêmen" (GATES; FINK, 2009, p. 335). As enzimas glicoproteínas, tem outras funções, auxiliar no reconhecimento das diferentes estruturas celulares presentes na superfície da membrana plasmática. Os valores de referência do PSA são classificados conforme a idade. Mensurar a concentração sanguínea de PSA é a conduta utilizada quando houver fatores como aumento da próstata, inflamação crescente, presença de câncer microscópico clinicamente insignificante e passagem de PSA para o soro. Associado a outros exames diagnósticos do CaP, o PSA é utilizado como um marcador no tratamento da doença, sendo que não deve ser usado isoladamente, por não haver sensibilidade e especificidade (FISCHBACH, 2005).

O estadiamento clínico (TNM) e o escore de Gleason, baseados na arquitetura histológica, são exames que definem qual o melhor tratamento para o paciente. O Sistema TNM avalia o grau de extensão anatômica da doença, conforme o tamanho do tumor $(\mathrm{T})$, a quantidade de linfonodos afetados $(\mathrm{N})$ e a presença ou não de metástases (M) (TNM, 2004). No escore de Gleason é atribuída uma nota de 1 a 5 para a diferenciação celular e outra com os mesmos valores para a distribuição do tumor. O produto final da soma das duas notas gerará uma pontuação de 1 a 10 (LIMA; CÂMARA; FONSECA, 2014).

Os tumores de próstata são classificados em risco baixo, intermediário e alto. Essa classificação leva em conta o valor do PSA, o escore de Gleason, e a fase da doença (conforme o toque retal e os exames de imagem), determinando seu grau de agressividade (MALUF, 2014, p. 61).

O tratamento do CaP é dividido conforme o estadiamento clínico, que vai indicar se a doença está localizada, localmente avançada ou alcançou um quadro metastásico, bem como indicar a expectativa de vida do paciente (LIMA; CÂMARA; FONSECA, 2014). Segundo Pollock et al. (2006, p.592) "Há uma diferença drástica na evolução dos pacientes com câncer de próstata com extensão extra prostática, em relação àqueles cuja doença está limitada à próstata". O objetivo do tratamento antineoplásico, em pacientes com Neoplasia Maligna de Próstata, é erradicar células malignas, procurando minimizar ao máximo os danos às células e tecidos vizinhos sadios.

A Prostatectomia Radical é aquela que remove todo o tecido prostático, as vesículas seminais e os tecidos adjacentes, está indicada para doença localizada, estágios T1 e T2, assim como a radioterapia, que tem o objetivo de destruir o tumor sem eliminar o tecido prostático. A impotência sexual, a incontinência urinária, irritação do reto, estreitamento da uretra são alguns dos efeitos colaterais destas terapias (POLLOCK et al., 2006). Kusnetzoff apud Silva 
e Ribeiro (2009, p. 52) citam que "[...] o tratamento por radiação, causa danos aos nervos destinados à ereção, sendo muito comum um distúrbio disfuncional sexual". Na Prostatectomia Radical, o suprimento nervoso é afetado durante a intervenção cirúrgica, acarretando em disfunção erétil, porém o desejo ou apetência sexual continuam presentes. As medicações, a desordem física e a prática cirúrgica utilizada no combate ao câncer podem afetar, diretamente, uma ou mais fases da resposta sexual (desejo, excitação, orgasmo e relaxamento após o orgasmo) (SILVA; RIBEIRO, 2009).

Braquiterapia corresponde ao modelo de radioterapia interna, que consiste na aplicação de sementes como fonte de radiação rente ao tumor. Associada a outras terapias, a Braquiterapia, assim como a radioterapia, estão indicadas a tumores limitados à próstata. A Braquiterapia é classificada como temporária ou permanente (MALUF; 2014).

No tratamento de câncer de próstata metastásico, o bloqueio androgênico é realizado inibindo parcial ou total a produção de testosterona. Os meios de tratamento podem ser medicamentosos ou a intervenção cirúrgica para a retirada dos testículos. Perda da libido, fogachos, osteoporose e a disfunção erétil são os principais efeitos colaterais da terapia.

[...] O carcinoma de próstata metastásico é considerado incurável. Sendo assim, o tratamento visa melhorar a sobrevida e a qualidade de vida. Os locais mais comuns de metástases são esqueleto axial, principalmente coluna lombar, fêmur proximal, pelve, coluna torácica, costela, esterno, crânio e úmero, em ordem decrescente de frequência. As lesões ósseas são tipicamente osteoblásticas. O acometimento visceral envolve pulmão, fígado e adrenal (LIMA; CÂMARA; FONSECA, 2014, p. 186).

Entre as complicações pós-tratamento, a disfunção sexual é um dos efeitos colaterais que mais afeta a qualidade de vida dos homens. Pinto et al. (2014, texto digital) destacam que o $\mathrm{CaP}$ “[...] é uma doença que afeta o imaginário masculino e que provoca alteração da autopercepção de sua identidade". Dúvidas quanto ao desempenho sexual são as maiores preocupações do homem com $\mathrm{CaP}$, pois ele vivencia um sofrimento mútuo, relacionado ao prognóstico da doença e às questões sexuais. "O tratamento do câncer de próstata afeta a masculinidade e contribui para que muitos homens se tornem impotentes" (TOFANI; VAZ, 2007, texto digital).

Do descobrimento dos primeiros sintomas ao diagnóstico, do tratamento ao acompanhamento médico, o CaP é uma doença que fere a imagem do homem, pois abrange aspectos culturais, simbólicos, sociais e econômicos presentes na construção da identidade masculina (PINTO et al., 2014). A estrutura emocional masculina é abalada gerando sofrimentos como a baixa autoestima, o desânimo e o recolhimento, levando o homem ao isolamento social e a dificuldade de aceitação da doença. O seu não enfrentamento pode 
se tornar uma barreira para a procura de ajuda profissional ou de seu grupo de amizades (TOFANI; VAZ, 2007, texto digital).

[...] O sentimento de impotência repercute como uma ferida na vida dos pacientes com câncer de próstata. Embora haja uma evolução da Medicina em termos de possibilidades de tratamento, observase, por se tratar de um órgão que afeta a sensibilidade sexual masculina, o sentimento de impotência está presente em todos os pacientes testados, mesmo naqueles com impotência transitória. Uma falha erétil pode antecipar o fracasso, produzir ou aumentar a ansiedade e a depressão no homem, diminuindo-lhe as sensações sexuais, alterando a fisiologia da ereção que pode levá-lo a um novo fracasso (TOFANI; VAZ, 2007, texto digital).

Os modelos de masculinidades são definidos nas sociedades durante a vida e ultrapassam características corporais do homem. A masculinidade não se limita apenas a anatomia masculina, mas ao comportamento, ao modo de vida e às regras atribuídas pela sociedade para que ele seja aceito. O modelo hegemônico de masculinidade é construído e legitimado entre diversificados modelos de masculinidade, podendo ser galgado na dominação e heterossexualidade, estando os demais modelos subordinados. "A masculinidade é um modelo que serve para formar a identidade de ser homem (ou a maneira de ser homem), prescrevendo as atitudes, os comportamentos e as emoções a serem seguidas" (GOMES, 2008, p.17). Segundo Silva (2004), a construção da identidade masculina está relacionada à diferença construída nos alicerces do sistema social e simbólico.

[...] Em primeira aproximação, parece ser fácil definir "identidade". A identidade é simplesmente aquilo que se é: "sou brasileiro", "sou negro", "sou heterossexual", "sou jovem", "sou homem". A identidade assim concebida parece ser uma positividade ("aquilo que sou"), uma característica independente, um "fato" autônomo. Nessa perspectiva, a identidade só tem como referência a si própria: ela é autocontida e autossuficiente (SILVA; 2004, p. 74).

Diante da sociedade, o modelo de homem fundamenta-se com bases na cultura do machismo. Desde criança, face às diferenças onde os modelos de homem e mulher estão montados e exemplificados nos atos e nos sentimentos, criam-se obstáculos para que o homem se expresse principalmente, no campo da saúde. Segundo Gomes (2003, texto digital), "a construção da masculinidade é atravessada por pontos de insegurança traduzidos, principalmente, pelo medo do homossexualismo e da impotência".

[...] No modelo de masculinidade a ser seguido, ressaltam-se as ideias de que o homem de verdade é solitário e reservado no que se refere às suas experiências pessoais, ou, quando muito superficial e 
prático, direcionado para agir e realizar atividades. Por outro lado, espera-se que o homem compreenda demandas emocionais de suas parceiras e de seus filhos, sendo cúmplice e sensível (GOMES, 2003, texto digital).

O comportamento do homem é submetido à reprovação ou ao apreço desde a infância, quando normas e princípios são atribuídos, de forma objetiva ou subjetiva, conforme a ótica do grupo social onde vivem. Características como ser forte, corajoso, invulnerável, insensível ou ser intocável podem ser atribuídas somente ao homem, levando-o a pensar que é vergonhoso ou sinal de fracasso realizar o exame preventivo do CaP. Para o autor, "Esses medos não podem ser vistos como simples "ignorância". Eles são reações ao fato de a imagem da masculinidade hegemônica estar sendo arranhada e devem ser discutidos para serem enfrentados" (GOMES, 2010, p. 41-42).

O exame digitálico retal da próstata pode ser visto pelo homem como uma violação de sua masculinidade, uma vez que certas partes do seu corpo são intocáveis. Constrangimento, dor ao ser penetrado, a ereção como resposta fisiológica fere e viola o modelo hegemônico de masculinidade. "Nesse contexto, o toque retal não toca apenas a próstata, mas também toca na masculinidade" (GOMES et al., 2008, texto digital). Tofani e $\operatorname{Vaz}(2007$, p. 197) afirmam que "[...] O sofrimento do homem, portador de câncer de próstata, afeta seu bem-estar físico e emocional, assim como a qualidade de vida em geral".

A atenção integral à saúde do homem implica em abordar a sexualidade masculina e a masculinidade. O que é ser homem? Qual o papel do homem na sociedade? $\mathrm{O}$ homem tem aderido aos programas de prevenção do $\mathrm{CaP}$ ? Pinto et al. (2014, texto digital) referem que "[...] na construção da identidade de ser homem com enfoque nos cuidados à saúde, muitos reprimem suas necessidades e se recusam a admitir a dor e o sofrimento, negando vulnerabilidades e fraquezas que são constituintes de todo ser humano". Assim, criar espaços para a promoção da saúde do homem, prevenção aos fatores de risco e adesão ao tratamento, tendo presente os aspectos culturais, são importantes para inserir o homem no processo de cura e superação do CaP (PINTO et al., 2014).

Partindo da relação processo saúde-doença do homem $\mathrm{x}$ sexualidade e masculinidade, o presente trabalho tem o propósito de caracterizar e sintetizar o que as pesquisas científicas brasileiras abordam sobre o $\mathrm{CaP}$, suas repercussões na sexualidade masculina e as dificuldades enfrentadas pelo homem, especialmente àquelas que afetam sua sexualidade.

\section{PROCEDIMENTOS METODOLÓGICOS}

Foi realizada Revisão Integrativa das produções científicas sobre o $\mathrm{CaP} \mathrm{e}$ suas repercussões na sexualidade masculina, segundo a metodologia proposta por COOPER (1989), a qual é composta por 5 etapas: formulação do problema; coleta de dados; avaliação, análise e interpretação dos dados; apresentação dos 
resultados e conclusões. Para isso, partiu-se da seguinte questão: De que modo a produção científica brasileira tem enfocado a relação entre o tratamento contra o $\mathrm{CaP}$ e a sexualidade masculina?

Para a coleta de dados, foram selecionadas palavras-chave presentes nos Descritores em Ciências da Saúde (DECS): sexualidade, próstata e neoplasias da próstata utilizadas de forma isolada e combinadas entre si com auxílio do operador de pesquisa 'and'. Foram incluídos os artigos publicados em língua portuguesa, disponíveis na íntegra e com livre acesso on-line, publicados entre o período de 2006 a 2015 e que abordaram a temática da relação entre o tratamento do câncer prostático e a sexualidade masculina.

Empreendeu-se a busca nos meses de agosto e setembro de 2015 na interface Biblioteca Virtual em Saúde (BVS), nas bases de dados eletrônicas Literatura Latino-Americana e do Caribe em Ciências da Saúde (LILACS) e a Scientific Eletronic Library Online (SCIELO). Foram encontrados 1.233 artigos científicos na BVS. Conforme as Bases de dados eletrônicas pesquisadas, 1.130 pertenciam a Literatura Latino Americana (LILACS) e 103 na Scientific Eletronic Library (SCIELO). Inicialmente foram lidos o título e o resumo de todos os artigos. Os artigos julgados pertinentes ao tema foram selecionados para leitura integral. Foram excluídos 598 artigos por ultrapassarem o período estabelecido para o estudo (2006 a 2015) e que traziam como foco principal as dificuldades da população masculina em realizar os exames preventivos do CaP. Restaram 635 publicações, sendo descartados 631por não atenderam ao objetivo e a questão norteadora do estudo. Assim, 4 artigos fizeram parte da amostra.

A avaliação dos dados iniciou mediante a elaboração de quadros sinópticos destinados a síntese das informações contidas em cada estudo. Posteriormente foram elaboradas categorias de acordo com os temas que emergirem da análise de cada publicação científica para proceder e análise e apresentação dos resultados (MINAYO, 2011). Os aspectos éticos foram observados quanto à explicação da autoria, citações e referências, conforme a Norma Brasileira 6023/2002.

\section{APRESENTAÇÃO E ANÁLISE DOS DADOS}

O quadro 1 apresenta os artigos que compuseram a amostra, os quais foram caracterizados segundo os autores e ano de publicação, o local de publicação e área de assunto da revista, conforme a classificação da BVS. 
Quadro 1 - Caracterização dos Artigos Revisados

\begin{tabular}{|c|c|c|c|}
\hline $\mathbf{N}^{\text {** }}$ & $\begin{array}{c}\text { Autores e ano de } \\
\text { publicação }\end{array}$ & $\begin{array}{c}\text { Local da } \\
\text { Publicação }\end{array}$ & Área** $^{*}$ \\
\hline 1 & Tofani; Vaz (2007) & RS & Psicologia \\
\hline 2 & $\begin{array}{c}\text { Moscheta; Santos } \\
(2012)\end{array}$ & RJ & Saúde Pública \\
\hline 3 & Araújo et al. (2013) & RJ & $\begin{array}{c}\text { Enfermagem; Prestação de cuidados } \\
\text { em saúde }\end{array}$ \\
\hline 4 & Pinto et al. (2014) & DF & Enfermagem \\
\hline
\end{tabular}

*Número utilizado para identificação do artigo.

**Conforme a classificação da BVS.

Fonte: elaborado pelo autor, 2015.

Dos 04 artigos pesquisados, 03 repetiram-se na base de dados LILACS, com os descritores Câncer da Próstata e Neoplasias da Próstata; 2 artigos duplicaram-se nas bases de dados LILACS E SCIELO, com o descritor Câncer da Próstata e apenas 1 artigo foi encontrado na base de dados LILACS, com o descritor Câncer da Próstata. O quadro 2 registra essas informações.

Quadro 2-Caracterização dos artigos segundo as bases de dados e os descritores

\begin{tabular}{|c|l|c|l|}
\hline $\mathbf{N}^{\mathbf{*}}$ & \multicolumn{1}{|c|}{ Título do Artigo } & Base de Dados & \multicolumn{1}{|c|}{ Descritor } \\
\hline 1 & $\begin{array}{l}\text { Câncer de próstata, sentimento } \\
\text { de impotência e fracassos ante os } \\
\text { cartões IV e VI do Rorschach }\end{array}$ & LILACS & Câncer da Próstata \\
\hline \multirow{2}{*}{2} & $\begin{array}{l}\text { Grupos de apoio para homens } \\
\text { com câncer de próstata: revisão } \\
\text { integrativa de literatura }\end{array}$ & LILACS & $\begin{array}{l}\text { Câncer da Próstata, } \\
\text { Neoplasias da Próstata }\end{array}$ \\
\cline { 2 - 4 } 3 & $\begin{array}{l}\text { As representações sociais de } \\
\text { homens sobre o câncer de } \\
\text { próstata }\end{array}$ & LILACS & $\begin{array}{l}\text { Câncer da Próstata, } \\
\text { Neoplasias da Próstata }\end{array}$ \\
\hline \multirow{2}{*}{4} & $\begin{array}{l}\text { Identidade do homem resiliente } \\
\text { no contexto de adoecer por câncer } \\
\text { de próstata: uma perspectiva } \\
\text { cultural }\end{array}$ & LILACS & $\begin{array}{l}\text { Câncer da Próstata, } \\
\text { Neoplasias da Próstata }\end{array}$ \\
\cline { 2 - 4 }
\end{tabular}

*Número utilizado para identificação do artigo.

Fonte: elaborado pelo autor, 2015.

O Quadro 3, abaixo, refere-se aos objetivos de cada estudo, conforme o número de identificação definido na Tabela 1. 
Quadro 3-Objetivos dos estudos

\begin{tabular}{|c|c|c|}
\hline $\mathbf{N}^{\mathbf{o *}}$ & \multicolumn{1}{|c|}{ OBJETIVOS } & Autores \\
\hline 1 & $\begin{array}{l}\text { Compreender os sentimentos de impotência e fracassos com } \\
\text { base em dados empíricos extraídos dos cartões IV e VI da } \\
\text { Técnica de Rorschach aplicado em vinte e cinco pacientes } \\
\text { com câncer de próstata em atendimento ambulatorial num } \\
\text { hospital de câncer. }\end{array}$ & Tofani; Vaz (2007) \\
\hline 2 & $\begin{array}{l}\text { Analisara contribuição dos estudosnacionaiseinternacionais } \\
\text { acerca da aplicaçâo de grupos de apoio psicológico como } \\
\text { estratégia de cuidado de pacientes diagnosticados com } \\
\text { Câncer de Próstata. }\end{array}$ & $\begin{array}{c}\text { Moscheta; Santos } \\
\text { (2012) }\end{array}$ \\
\hline 3 & $\begin{array}{l}\text { Identificar as representações de homens sobre o Câncer de } \\
\text { Próstata e suas masculinidades frente à doença e analisar } \\
\text { suas implicações para a saúde. }\end{array}$ & $\begin{array}{c}\text { Araújo et al. } \\
\text { (2013) }\end{array}$ \\
\hline 4 & $\begin{array}{l}\text { Conhecer o contexto do homem resiliente ao adoecer por } \\
\text { Câncer de Próstata. }\end{array}$ & Pinto et al. (2014) \\
\hline
\end{tabular}

*Número utilizado para identificação do artigo.

Fonte: elaborado pelo autor, 2015.

Em relação à metodologia e aos sujeitos da pesquisa, o estudo de TOFANI; VAZ (2009) extraiu os dados empíricos dos cartões IV e VI do Rorschach - sistema Klopfer - aplicado em pacientes portadores de CaP. Participaram da pesquisa 25 pacientes situados na faixa etária de 48 e 83 anos, com maior concentração $(n=19)$ na faixa entre 62 e 74 anos em atendimento ambulatorial com nível sócio econômico médio/médio baixo pela renda. Dezessete participantes informaram primeiro grau incompleto como escolaridade, quatro, primeiro grau completo, três, segundo grau completo e um com nível superior.

O estudo de Moscheta e Santos (2012) caracterizou-se como uma revisão integrativa da literatura norteada pela questão: qual é a contribuição dos grupos de apoio psicológico no cuidado de homens com câncer de próstata?

O estudo de Araújo et al., (2013) foi uma pesquisa exploratória, do tipo estudo de caso com abordagem qualitativa, procedida pela técnica de análise de conteúdo. Participaram do estudo 20 sujeitos diagnosticados a mais de um ano com CaP que realizam esporadicamente tratamento na instituição Clínica Urológica do Hospital Ophir (HOL) no município de Belém (Pará) sendo que 12 são prostatectomizados e 8 recebem tratamentos quimioterápicos para controle da doença. A faixa etária dos sujeitos do estudo variou entre 50 e 71 anos de idade, sendo que 12 tinham mais de 60 anos e 8 tinham entre 50 e 60 anos, 14 dos participantes tinham nível de escolaridade médio completo e 6 tinham o nível de escolaridade fundamental incompleto, todos com renda de até dois salários mínimos, 8 residentes no município de Belém e 12 provenientes de municípios do interior do estado do Pará. 
Por fim, o estudo de Pinto et al. (2014) trouxe os dados sobre "A resiliência como estratégia de enfrentamento para sobreviventes ao câncer". Tratou-se de um estudo etnográfico, de caráter qualitativo, apoiado em Geertz (1989) a respeito da cultura, e em Woodward (2012), com relação à identidade. A pesquisa teve a participação de dois homens, ambos com 69 anos de idade, sobreviventes ao $\mathrm{CaP}$, residentes no RS, casados e aposentados, que foram atendidos na Unidade de Oncologia do Hospital Escola da Universidade Federal de Pelotas (UFPel).

Tomando em consideração a análise dos quatro artigos selecionados destaca-se a escassez na literatura nacional da produção científica relacionada ao tema tratamento do $\mathrm{CaP}$ e a sexualidade masculina. Foram encontradas unidades de sentido que permearam as quatro publicações e que contribuíram para a criação de categorias temáticas, as quais serão apresentadas a seguir (MINAYO, 2011).

\section{Formação da identidade masculina e do cuidado à saúde no contexto social}

Três autores abordaram a formação da identidade masculina e do cuidado à saúde no contexto social (ARAÚJO et al., 2013; TOFANI; VAZ, 2007; PINTO et al., 2014). Para Araújo et al. (2013), as representações sociais dos homens sobre masculinidade, as atitudes masculinas e os atos introjetados são reconhecidos e socializados como comuns, sendo indispensáveis para construção de suas identidades como homens.

A masculinidade é um conceito que se destaca em várias culturas e está impregnado de padrões e exigências sociais. Uma vez internalizados, funcionam como registros, impelindo o homem a exercer e assumir papéis culturais de poderoso, salvador, protetor e provedor. Nesse contexto, a preocupação com a saúde passa a ser função feminina (TOFANI; VAZ, 2007).

Segundo Pinto et al. (2014), a identidade do homem é o reflexo da construção histórica, social e cultural de "ser homem". Os autores, em seu estudo, pesquisaram dois sujeitos com CaP. Um deles (CB) estudou até a $5^{\circ}$ série do Ensino fundamental, é da raça negra. Recebeu o diagnóstico de $\mathrm{CaP}$ em estádio inicial há 3 anos, não realizou procedimentos cirúrgicos, nem hormonioterapia, somente sessões de radioterapia. Mantém acompanhamento médico semestralmente. Esse sujeito evidenciou a noção de que é o homem que deve tomar as decisões na família perante a sociedade. Apesar de serem divididos os problemas no ambiente familiar, quem dá à última e decisiva palavra é ele. Aprendeu a ser independente desde a infância, pois vivenciou o abandono afetivo e físico por parte do pai. Não tinha contato com seus irmãos, nem com os vizinhos. Para ele o câncer deve ser enfrentado "sem alarde". Os autores acreditam que esse modo de encarar a enfermidade possa ter origem na construção histórica, social e cultural permeada pelo abandono familiar. Para 
esse sujeito, que se caracterizou como típico gaúcho, contador de histórias, ele deve mostrar-se forte (PINTO et al. 2014).

O outro sujeito (ESM) é semianalfabeto e de raça caucasiana. Recebeu o diagnóstico de $\mathrm{CaP}$ em estádio avançado, realizou cirurgia de prostatectomia total há 10 anos. Mantém tratamento de hormonioterapia mensalmente e faz acompanhamento com oncologista. Esse sujeito desenvolveu uma ligação muito forte com a família e pedia ajuda a filha para tomar decisões em relação a sua vida. Apesar de pouca escolaridade, buscou em diversas atividades profissionais a sua afirmação social o que fundamentou a sua identidade de homem como pai, marido e provedor do lar. Trabalhou 22 anos em granja, dentro da água, no barro, no frio e na geada. Associou a ardência urinária que sentia ao clima e se acostumou ao sintoma, classificando-o como normal, fato que foi ao encontro da construção social relacionada à saúde do homem que ainda o sugestiona como "invulnerável" (PINTO et al., 2014).

Pinto et al. (2014) concluem que a resiliência presente nos dois sujeitos do estudo não surgiu com o $\mathrm{CaP}$ e sim ela permeou as suas trajetórias de vida construídas por meio do trabalho e das relações familiares. O trabalho representou uma forma de ser homem, condição primordial para sua autonomia enquanto ser humano. Também, o fato desses homens serem gaúchos, acreditase que a cultura do RS possa ter refletido em como eles significam suas experiências na doença uma vez que, historicamente, os homens são entendidos como fortes, corajosos, viris, que lutam por seus ideais e que não se expõem como frágeis.

Necessita-se compreender o homem como ser histórico e cultural, que constrói e significa sua identidade mediante as teias de relação por ele construídas e que dão sentido ao modo como ele entende e vivencia as situações, inclusive de doença, como o CaP. O homem que antes era forte e viril, devido à doença, precisa aprender a lidar com limitações e sentimentos não convencionados - pelo menos não claramente - e necessita reconstruir a sua identidade numa nova perspectiva de ser homem (PINTO et al., 2014).

Independentemente do tipo de câncer e da duração do tratamento, vivenciar um processo de adoecimento nunca é uma experiência fácil. Para os homens distanciados dos serviços de saúde por interfaces de sua identidade, a procura por auxílio do sistema de saúde precocemente, não costuma ser rotineira. Diante disso, a importância da atuação da equipe multiprofissional nesse processo para auxilia-los a atentar para o cuidado da própria saúde. É necessário os profissionais atentem para as questões sociais e culturais nas quais os homens se inserem ao descobrirem-se com uma doença crônica como o CaP. Compreender como os homens constroem a resiliência possibilita que a equipe se aproxime destes pacientes e construa com ela as ações e cuidados voltados para as suas reais necessidades (PINTO et al., 2014). 


\section{Repercussões do tratamento do câncer de próstata}

As repercussões do tratamento do câncer de próstata foram enfocadas por dois autores (TOFANI; VAZ, 2007; ARAÚJO et al., 2013).

$\mathrm{O} \mathrm{CaP}$ possui um impacto social marcante para o homem devido a ser um órgão presente no senso comum como responsável pelo desejo e prazer sexual, pela reprodução e ereção masculina. No que concerne à reprodução, a próstata está relacionada à liberação de uma secreção, pelo fornecimento do prazer sexual e pela vitalidade do universo masculino, concebendo ao homem o poder simbólico de ser viril, dominante do prazer sexual e capaz socialmente (ARAÚJO et al., 2013).

O CaP é uma doença agressiva, principalmente quando o tratamento é iniciado tardiamente, contribuindo para que o paciente se volte para si mesmo, mobilizado em relação à sexualidade e revisando sua vida para que possa enfrentá-la diante desta nova contingência. Os homens apresentaram várias respostas relacionadas à sexualidade que podem ser indicadoras de conflitos com a própria sexualidade, de medo e angústia frente à genitalidade (TOFANI; VAZ, 2007).

A retirada da próstata ocasiona a ausência da secreção prostática, tendo como consequência a menor vitalidade dos espermatozoides e a diminuição do líquido seminal, o que no imaginário do homem ocasionaria a diminuição da ereção peniana e de todo desenvolvimento sexual, força e prazer. O simbolismo masculino relacionado à próstata é indispensável para a sua caracterização como homem frente à sociedade e sua disfunção é transgressora desta caracterização (ARAÚJO et al., 2013).

Pacientes que fazem uso da hormonioterapia e que se submetem a orquidectomia apresentam perda do desejo sexual, o que também contribui para ameaçar a virilidade masculina. Assim, o homem passa pelo sofrimento psíquico de não sentir mais vontade de manter relações sexuais, de se sentir menos homem. Tal fato vai contra a virilidade masculina que é cultivada pelo meio social que habita e define o homem como detentor do controle tanto social como do seu próprio corpo (ARAÚJO et al., 2013).

A impotência causada pela doença ou pelos tratamentos, mesmo que transitória, é vivenciada como a castração ou a própria morte para os homens, que se sentem desvitalizados. O medo de lidar com os impulsos gera inibição fazendo com que eles procurem fugir de sua realidade, entrando em depressão e aumentando o nível de ansiedade. Estes aspectos relacionam-se aos mitos culturais: sexo é da responsabilidade masculina, ereção $=$ virilidade $=$ homem exitoso. A preocupação com a possibilidade da perda da "potência" no sentido global faz com que estes homens se apresentem inibidos, sintam-se fracassados e retraídos individual e socialmente, sem conseguir manifestar afeto (TOFANI; VAZ, 2007). 
A morte sustenta-se em uma masculinidade socialmente alicerçada no homem "potente e viril", não restando espaço para questões de finitude na cultura ocidental no modo de "ser homem" (ARAÚJO et al., 2013).

Araújo et al. (2013) afirmam que o CaP é uma patologia que impede o homem de ter uma vida normal, levando ao isolamento e exclusão do convívio social devido as manifestações clínicas cotidianas derivadas da doença como o descontrole sobre algumas de suas funções fisiológicas. Essa situação pode levar ao retardo no diagnóstico do $\mathrm{CaP}$ devido à dificuldade que os homens têm, em geral, de realizar o exame de toque retal.

Araújo et al. (2013) concluem que os profissionais da saúde, em especial, o enfermeiro, deve compreender os homens adoecidos pela apropriação de um saber consensual, sendo este gerado entre os indivíduos, de modo a guiar suas ações e enfrentar o CaP. A compreensão de alguém que compartilha o lado pessoal, imprime seu toque e compartilha com o grupo social permite transformar uma realidade que gera ansiedade.

\section{Os grupos de apoio ao indivíduo com $\mathrm{CaP}$}

A última categoria deste estudo aborda os grupos de apoio ao indivíduo com CaP. Dois autores fizeram menção ao tema (MOSCHETA; SANTOS, 2012; ARAÚJO et al., 2013).

Os grupos de apoio aos homens com $\mathrm{CaP}$ funcionam como estratégia complementar de cuidado, cuja principal característica é oferecer um contexto de socialização e compartilhamento de sentimentos e emoções, ambos necessários para o enfrentamento de uma doença grave que carrega o estigma de ser potencialmente fatal. Por ser uma patologia discriminada e revestida de certos tabus na cultura ocidental, a vivência com a doença pode determinar o rompimento de relações sociais importantes e necessárias para o bem-estar psicossocial do paciente. Oferecer apoio psicológico por meio de grupos permite compreender as condições que motivam a participação das pessoas em tais grupos e os fatores terapêuticos que legitimam essa estratégia de cuidado dentre outras ações, além de fornecer subsídios para o planejamento e implantação de atenção à saúde a estes pacientes em diferentes contextos (MOSCHETA; SANTOS, 2012).

Os principais benefícios dos grupos de apoio aos pacientes com $\mathrm{CaP}$ são: amparar as angustias despertadas durante o enfrentamento da doença, a reabilitação psicossocial e a possibilidade de criação ou manutenção de uma rede de apoio psicossocial, considerada fundamental para auxiliar no tratamento da doença. A adesão aos grupos de apoio gera uma atitude positiva, sendo um espaço em que ocorre o compartilhamento de informações sobre a doença, o tratamento, as adaptações das sequelas transitórias ou definitivas, adaptações sexuais, adesão ao tratamento, o relacionamento com o cônjuge e a criação de uma rede de apoio às mulheres para obterem informações do 
$\mathrm{CaP}$ para ajudar o companheiro atuando como cosobreviventes, facilitadoras e apoiadoras sociais (MOSCHETA; SANTOS, 2012).

No estudo conduzido por Moscheta e Santos (2012) os pacientes que procuram os grupos de apoio são aqueles que possuem nível baixo de escolaridade, vivem em isolamento social ou que possuem deficiência da rede social de apoio. São pacientes que moram em grandes centros urbanos e que estão mais propensos a procurar ajuda nos grupos de apoio, pois, as grandes cidades, em geral, determinam certo enfraquecimento da rede social e das relações afetivas. Os temas abordados nos grupos de apoio incluem a preocupação do homem em ficar impotente sexualmente na cirurgia de retirada da próstata, que somado a incontinência urinária, possuem um alto potencial de limitação da vida social.

No contexto de "ser homem" os grupos de apoio permitem construir, reconfigurar e redefinir significados atribuídos a sexualidade, a atividade sexual e a masculinidade. O grupo é importante para a negociação de significados de formas de intimidade, de relações sexuais e abstinência sexual. Também, de discussão e debate sobre a identidade incluindo a reconfiguração da relação conjugal e a criação de uma nova identidade social. Na enfermagem, o enfermeiro pode promover estratégias que possibilitem o envolvimento do paciente, da família, da comunidade no preparo para prevenção e enfrentamento da doença (ARAÚJO et al., 2013).

Araújo et al. (2013) concluem que o CaP é uma doença ligada ao contexto social que proporciona momentos de não inclusão, dor, tristeza, troca de experiências. Os riscos à saúde, quando o homem negligencia o exame de toque retal, estão ligados à comportamentos socioculturais intrínsecos ao meio onde estão inseridos, o qual descreve o homem como um ser forte e inviolável, e devem ser debatidos com flexibilidade. A troca de experiências no grupo frente às representações sociais dadas ao $\mathrm{CaP}$ auxilia os homens a formar conceitos e opiniões sobre a doença e como conduzir o modo de vida no cotidiano. As opiniões apresentadas pelos sujeitos do grupo são importantes para que o profissional de saúde compreenda as diversas relações que se estabelecem entre o $\mathrm{CaP}$ e a vida social.

\section{CONSIDERAÇÕES FINAIS}

A análise das publicações científicas brasileiras que se propuseram a identificar a relação entre o $\mathrm{CaP}$ e a sexualidade masculina permitiu concluir que o adoecimento e seu consequente tratamento possuem grande impacto na imagem que o homem tem sobre sua sexualidade, estando relacionado ao medo de tornar-se sexualmente impotente, uma vez que a próstata faz parte do "imaginário" masculino de virilidade. Assim, pode-se dizer que os medos e angústias são individualizados e estão em acordo com a interpretação que o homem dá ao processo de seu adoecimento, o qual é alicerçado na construção 
da identidade masculina, na história de vida de cada um e em questões culturais diversificadas.

A construção de um modelo hegemônico de masculinidade, a "simbologia" atribuída à próstata e o CaP visto como ameaça ao "ser homem masculino" foram pontos identificados nos estudos que atingem o imaginário masculino e ocasionam alterações na autopercepção sobre sua sexualidade. $\mathrm{O}$ imaginário relacionado à masculinidade reflete-se no comportamento do homem frente ao $\mathrm{CaP}$. A próstata caracteriza-se simbolicamente como um órgão intimamente ligado a um ser "potente, capaz e viril" e fez com que o homem adoecido precise reconstruir novos conceitos sobre sua sexualidade e ao modelo hegemônico de masculinidade.

Os profissionais da saúde, no processo do cuidar, devem considerar o homem como um ser integral, histórico e cultural, formado pelas dimensões biológica, psicológica e social. A sexualidade é um componente que integra o ser humano. Incluir a atenção à sexualidade no cuidado ao homem requer preparo e sensibilidade por parte dos profissionais, pois é um tema ainda carregado de tabus e preconceitos, mas que requer seu enfrentamento.

O desconhecimento por parte dos homens perante a doença deve ser reparado por todos os profissionais de saúde e o apoio afetivo-emocional, oriundo da família, deve ser enfatizado para seu melhor enfrentamento, com abordagens teóricas e práticas sobre a patologia.

Os grupos de apoio possibilitam aos homens a redefinição destes conceitos, compartilhando experiências e angústias e contribuindo para enfrentamento da doença. A implantação de um espaço para atividades grupais aos homens acometidos com CaP possibilita trabalhar angústias e sentimentos, definir e redefinir conceitos sobre masculinidade numa sociedade em que o modelo de homem ainda é visto com um ser "potente, invulnerável, forte e viril". Tal fato foi detectado em um dos estudos, mostrando os benefícios como adesão do homem ao tratamento e autocuidado.

Sugere-se que os profissionais da saúde façam parcerias com diversas lideranças da comunidade de modo a implementar atividades educativas em diferentes espaços, como escolas, grupos de jovens, associações de moradores, sindicatos, igrejas, clubes, de modo que este tema seja abordado de forma precoce e permanente na sociedade, envolvendo homens e mulheres.

Como limitações do estudo destaca-se a escassez de artigos científicos publicados nas bases de dados pesquisadas sobre pacientes diagnosticados com $\mathrm{CaP}$ e as consequências do tratamento na sexualidade masculina. Considera-se que se outras bases de dados tivessem sido incluídas, novos estudos poderiam ter sido analisados e a análise seria ampliada.

Por fim, frente à complexidade das questões levantadas sobre o Cap e sua relação com a sexualidade masculina, espera-se instigar os profissionais para 
que novos estudos sobre esta temática sejam realizados, de modo a contribuir para elevar a qualidade de vida da população masculina afetada pelo $\mathrm{CaP}$.

\section{REFERÊNCIAS}

ARAÚJO, Jeferson. et al. As representações sociais de homens sobre câncer de próstata. Revista de Pesquisa Cuidado é Fundamental On line. v.5, n 2. RJ, abr./jun. 2013. Disponível em: <http://www.seer.unirio.br/index.php/cuidadofundamental/ article/viewFile/2135/pdf_800>. Acesso em: ago. de 2015.

BARACAT, Fausto F. Fernandes Jr, Hézio J. SILVA, Maria J. Cancerologia Atual: um enfoque multidisciplinar. SP: Roca, 2000.

COOPER, H. M. Scientific guidelines for condocting integrative research reviews. Review of Educational Research, v. 52, p. 291-302, 1982.

FISCHBACH, Frances. Manual de Enfermagem. Exames laboratoriais e diagnósticos. 7. ed. Rio de Janeiro: Guanabara Koogan, .2005.

GATES, Rose A.; FINK, Regina M. Segredos em Enfermagem oncológica. 3. ed. São Paulo: Artmed, 2009.

GOMES, Romeu et al. As arranhaduras da masculinidade: uma discussão sobre o toque retal como medida de prevenção do câncer prostático. Ciênc. saúde coletiva, Rio de Janeiro, v. 13, n. 6, nov./dec. 2008. Disponível em: <http:/ /www.scielo.br/ scielo.php?script=sci_arttext\&pid=S1413-81232008000600033 >. Acesso em: 09 mar. 2015.

A saúde do homem em foco. São Paulo: UNESP, 2010.

. Sexualidade masculina e saúde do homem: proposta para uma discussão. Ciência e saúde coletiva, 2003. Disponível em: $<$ https://www.nescon. medicina. ufmg.br/biblioteca/imagem/0764.pdf >. Acesso em: 04 mar. 2015.

GUIMARÃES, José L. M.; ROSA, Daniela D. Rotinas em Oncologia. Porto Alegre: Artmed, 2008.

HOLICK, Michael F. Vitamina D. Como um tratamento tão simples pode reverter doenças tão importantes. São Paulo: Fundamento Educacional, 2010.

INSTITUTO NACIONAL DE CÂNCER JOSÉ ALENCAR GOMES DA SILVA (INCA). Estimativa 2014: incidência de câncer no Brasil. Disponível em: <http:/ / www.inca. gov.br/estimativa/2014/estimativa-24042014.pdf>. Acesso em: 29 abr. 2015.

LIMA, Daniel X.; CÂMARA, Francisco de P.; FONSECA, Carlos E. C. Urologia bases do diagnóstico e tratamento. São Paulo: Belo Horizonte: Rio de Janeiro: Atheneu, 2014. 
LOPES, Ademar; CHAMMAS, Roger; IYEYASU, Hirofumi. Oncologia para a graduação. 3. ed. São Paulo: Lemar, 2013.

MALUF, Fernando C. Vencer o câncer de próstata. Evitar tratar curar. 1. ed. São Paulo: Dentrix, 2014.

MARIEB, Elaine N.; HOEHN, Katja. Anatomia e fisiologia. 3. ed. Porto Alegre: Artmed, 2009.

MINAYO, Maria C. de S. O desafio do conhecimento: pesquisa qualitativa em saúde. São Paulo: Hucitec, 2011.

MOSCHETA, Murilo S.; SANTOS, Manoel A. S. Grupos de apoio para homens com câncer de próstata: revisão integrativa da literatura. Ciência e Saúde Coletiva, v. 17, n. 5. mai 2012. Disponível em: <http://www.scielosp.org/scielo.php?script=sci arttext\&pid=S1413-81232012000500016\&lng=pt\&nrm=iso\&tlng=pt $>$. Acesso em: ago 2015.

PINTO, Bruna Knob et al. Identidade do homem resiliente no contexto de adoecer por câncer de próstata: uma perspectiva cultural. RevBrasEnferm. v. 67, n. 6, p. 942-8, nov./dez. 2014. Disponível em: <http://www.scielo. br/pdf/reben/v67n6/00347167-reben-67-06-0942.pdf>. Acesso em: 04 mar. 2015.

POLOCK, Raphael E. et al. (Editores). Manual de oncologia clínica UICC. 8. ed. São Paulo: Fundação Oncocentro de São Paulo, 2006.

SANTOS, Carlos E. R.; MELLO, Eduardo L. R. de. Manual de cirurgia oncológica. 2. ed. São Paulo: Tecmedd, 2008.

SILVA, Rosenilda Moura da; RIBEIRO, Maria Alexina. Sexualidade e câncer. Vivência de casais no estágio avançado da doença. Curitiba: Juruá, 2009.

SILVA, Tomaz Tadeu da (Org.) Identidade e diferença. A perspectiva dos Estudos Culturais. 3. ed. Rio de Janeiro: Vozes, 2004.

TOFANI, Ana C. A.; VAZ, Cícero E. Câncer de próstata, sentimento de impotência e fracassos ante os cartões IV e VI do Rorschach. Revista Interamericana de Psicologia, v. 41, n. 2, p. 197-204. Pontifícia Universidade Católica do Rio Grande do Sul, Porto Alegre, Brasil, 2007. Disponível em: <http:/ / www.psicorip.org/Resumos/PerP/RIP/ RIP041a5/RIP04121.pdf >. Acesso em: 04 mar. 2015.

TORTORA, Gerard J.; DERRICKSON, Bryan. Corpo humano: fundamentos de anatomia e fisiologia. 8. ed. Porto Alegre, 2012. 